\title{
Effort Monitoring and Tracking System
}

\author{
T. Rajesh Kumar ${ }^{1}$, Dama Anand ${ }^{1}$, G. Rama Krishna Srinivas ${ }^{1}$, Debnath \\ Bhattacharyya $^{2}$ and Hye-jin $\mathrm{Kim}^{3}$ \\ ${ }^{1}$ Department of Computer Science and Engineering, KL University, \\ Vaddeswaram, Guntur, India \\ \{t.rajesh61074, ananddama89\}@kluniversity.in, \\ ${ }^{2}$ Department of Computer Science and Engineering, \\ Vignan's Institute of Information Technology, \\ Duvvada, Visakhapatnam, India \\ ${ }^{3}$ Sungshin Women's University, \\ 2, Bomun-ro 34da-gil, Seongbuk-gu, \\ Seoul, Korea \\ srinivas12ram@gmail.com,debnathb@gmail.com,hyejinaa@daumnet
} (Corresponding Author)

Abstract

Prime Leading organizations will use the web portal for effort monitoring and tracking. This portal is used to store and analyze the employee effort from various $R \& D$ departments. This portal provides a front nd environment for employees/management of an organization to keep a track of histhen effort. It is olso expected to use SharePoint advanced features such as content management, alers information management policies, collaboration features, reporting, and analytics senvices.

Keywords: Effort Tracking System, Share Point, Content Management

\section{Introduction}

The employee Effort tracking Solution is a new application which is being developed to track and measure the effort spent by $\mathrm{R} \& \mathrm{D}$. The application is being developed in multiple phases and this version of the document explains the detailed design of the Phase 1 solution. The applicafion is being built as a web-based solution, hosted on SharePoint 2013 platform. The Effort Tracking System (ETS) would ensure a more streamlined and secured approach to track hours against defined work categories, reporting and data analysis. The development of the solution will be executed in multiple phases.

The Effort Tracking System is used to store and analyze the employee effort from various R\&D departments. It provides a front end environment for employees/management of an organization to keep a track of his/her effort. It is also expected to use SharePoint advanced features such as content management, alerts, information management policies (especially content retention), collaboration features, reporting, and analytics services. One of the reasons identified as the cause for less effort done by some of the employee and some of them are doing lots of work with hectic schedule.

\subsection{Need for Effort Tracking System}

Effort tracking play a significant role in any organization. This activity is pain of approximately every manager. Tracking of effort spent is an essential requirement from senior management. Tracking of effort will give clear picture about the utilization of manpower in various projects. Effort Tracking System has been designed to monitor and 
track the time and effort invested on projects and other organizational activities by an employee.

a) The system helps to gain more insights about the set of tasks in which the employee is currently involved.

b) Effort Tracking System can be used as a workload management system where heavy and complex modules of a project can be detected by the time spent by the employees on the module. Job assignments can be adjusted based on the workload.

c) Software changes are implemented incrementally which further leads to issue of accurate effort tracking in projects.

d) Predicting effort variance in a project manually does not give precise picture of project status and health of a project. Manual calculation of effort variance can misguide senior management. So corrective actions required to be taken in the project at right time will be missed which may impact project seriously.

e) The actual effort devoted by the employees can be compared with the estimated effort required for a task. Based on the comparison, effort variance can be determined which can be use for revising estimation of project.

f) Reports can be generated for the senior management to formulate appropriate decisions regarding manpower, project progress, cost invested and investment decision on upcoming project.

\subsection{Major Challenges Faced}

Implementation of Effort tracking system faces some of major challenges which eventually lead to a further evolved system.

a) Major hurdle for designing and implementing effort tracking system is integration of data from different sources like REID attendance system for capturing attendance, project plan from Microsoft plan.

b) There are short of experience of new project managers to prepare project plan in detail so that effort tracking will be more precise.

c) There is lack of understanding by team members to provide the efforts spent in the project accurately.

d) Team members fill efforts based on a summarized or abstract view of the project rather than breaking downthe efforts to miniature level.

e) One of the major challenges is to guide project team to use effort tracking system because they are adapted to manual system. Implementation of system is successful only when it used by all project teams in the organization to fill the effort spent in project in precise manner.

\subsection{Business Problem}

One of the reasons identified as the cause for less effort done by some of the employee and some of them are doing lots of work with hectic schedule.

\section{Proposed Requirements of Effort Tracking System}

The Effort Tracking System offers a comprehensive proposal for capturing effort data from many countries (all over the world) and making that data available to back end systems for application in a single domain. Capturing, uploading, distributing, and processing effort data will require resolution of a number of complex technical challenges.

The goal of the proposal offered in this document is to provide a flexible solution that makes the effort data available globally using single domain application.

Proposed requirement to be divided into 3 parts: 
- Collect the data from PeopleSoft update the system. Interface will pick the file using schedule SSIS job. Interface for master data in SharePoint.

- Custom user interface to collect the effort tracking data on a weekly basis for employee.

- The process is capable of displaying reports and do the data analysis on effort tracking data.

\subsection{Requirement}

System should be able to process master data from the system which will be provided in flat file format. All R\&D employees will be able to enter effort tracking data on a weekly basis. Manager can view the effort data in his/her department or as per department hierarchy. Manager/ Administrator/ Senior Executives /Product Management Organization group can do the data analysis as per there privilege in the system. Reminder mail will be sent to employee for submitting the effort for current week.

\subsection{Assumptions}

- Application will not communicate directly with any other systems (people soft).

- Flat files will be shared on a shared directory of production box. First row will contain the column name. Each record shouid be placed in one Jiner and columns in that with "l" separated. File should be saved in UTF- 8 format. Date should be in YYYY-MM-DD. All columns will be in sequence.

- Administrative account and service account should be ayailable in the system.

- Should have the access on DNS to create new zone for SharePoint apps (it should be taken care by customer network team).

\subsection{Configuration and Security}

- For GPG encryption gpg4win-2.1.0 needs to be installed.

- For Multilingual Japanese langtage needs to be installed.

- SMTP server needs to be configured for mailing.

- GPG encryption key will be created against SQL Server Agent account and shared with HGST IT for file encryption.

- SSIS job will be configured in SQL Server Agent. All the jobs will be scheduled when the system is inidle state [USA midnight time].

- IIS will be configured

- SharePoint Farm will be configured

- Computer name should be without "_".

\subsection{Functional Components}

Master Data: Master Data will be residing in SharePoint. Some of the data would be populated from external system and other are populated in SharePoint itself. A Predefined flat file will be shared within production box. First row will contain the column name. Each record should be placed in one liner and columns in that with "|" separated. File should be saved in UTF-8 format. Date should be in YYYY-MM-DD format. Data will be imported into sql by using SSIS package. Data will be automatically populated in SharePoint via BCS.A UI will be available within SharePoint to update the master data.

Transaction: All R\&D employees will be required to enter effort tracking data on a weekly basis. This includes employees, managers, executives, and contractors. There will be three screens for each user role [Employee / Manager /Administrator]. Employee will enter his or her data. Manager /Administrator will enter the data on behalf of employee. 
Transaction Report: Manager can view the effort data in his/her department or as per department hierarchy. Two kinds of reports are available

HC Report-Manager Weekly: Manager would get an email on weekly basis against their department or as department hierarchy. A link will be there to open the report. Report would contain the effort data against the current week.

HC Report- Manager Ad Hoc: Manager can generate the report by providing start month and end month. It would display the effort data on week wise.

Data Warehouse: Set up the analysis data base based on following dimensions tables and fact table. Data will be transfer from ETS to Data warehouse system on weekly basis.

\section{Dimension tables}

- Employee dimension table

- Department dimension table

- Cost center dimension table

- Product dimension table

- Technology platform dimension table

- Project dimension table

- Admin \& management dimension table

- Work activity breakdown dimension table

- Time dimension

Fact table

- EFFORTTRACKING Table

Cube: A cube is defined by its measures and dimensions. The measures and dimensions in a cube are derived from the tables and viewsin the data source view on which the cube is based.

Analysis Report: Head count anliytics report would be generated using CUBE. Within the report we will maintain the time dimension (Month, Fiscal Quarter, and Calendar Quarter). Effort will be lisplayed against Work category (e.g. Product, Project, Technology etc.), or work activity.

\section{Architecture of Effort Tracking System}

ETS Application is to develop an intranet based single streamlined web application using SharePoin 2013.It would be hosted in AWS.

The following diagram outlines the proposed physical architecture of the Effort Tracking System (ETS) 


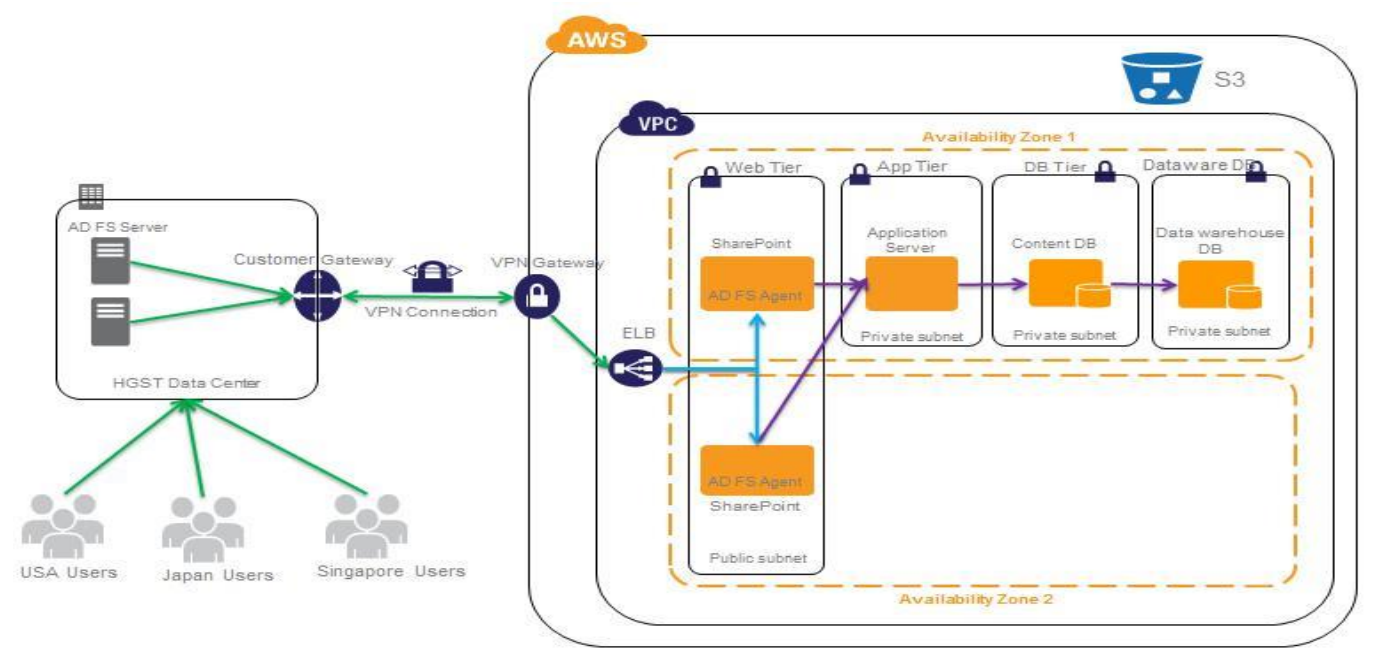

Figure 1. Proposed Physical Architecture

Server farms architecture has been divided in 3 categories Small Medium, Large. Based on current scope and number of user we have proposed for medium server farm to host the ETS system.

1. Transactions

2. Reports

3. Lists

The following figure depicts how they are connected to each other

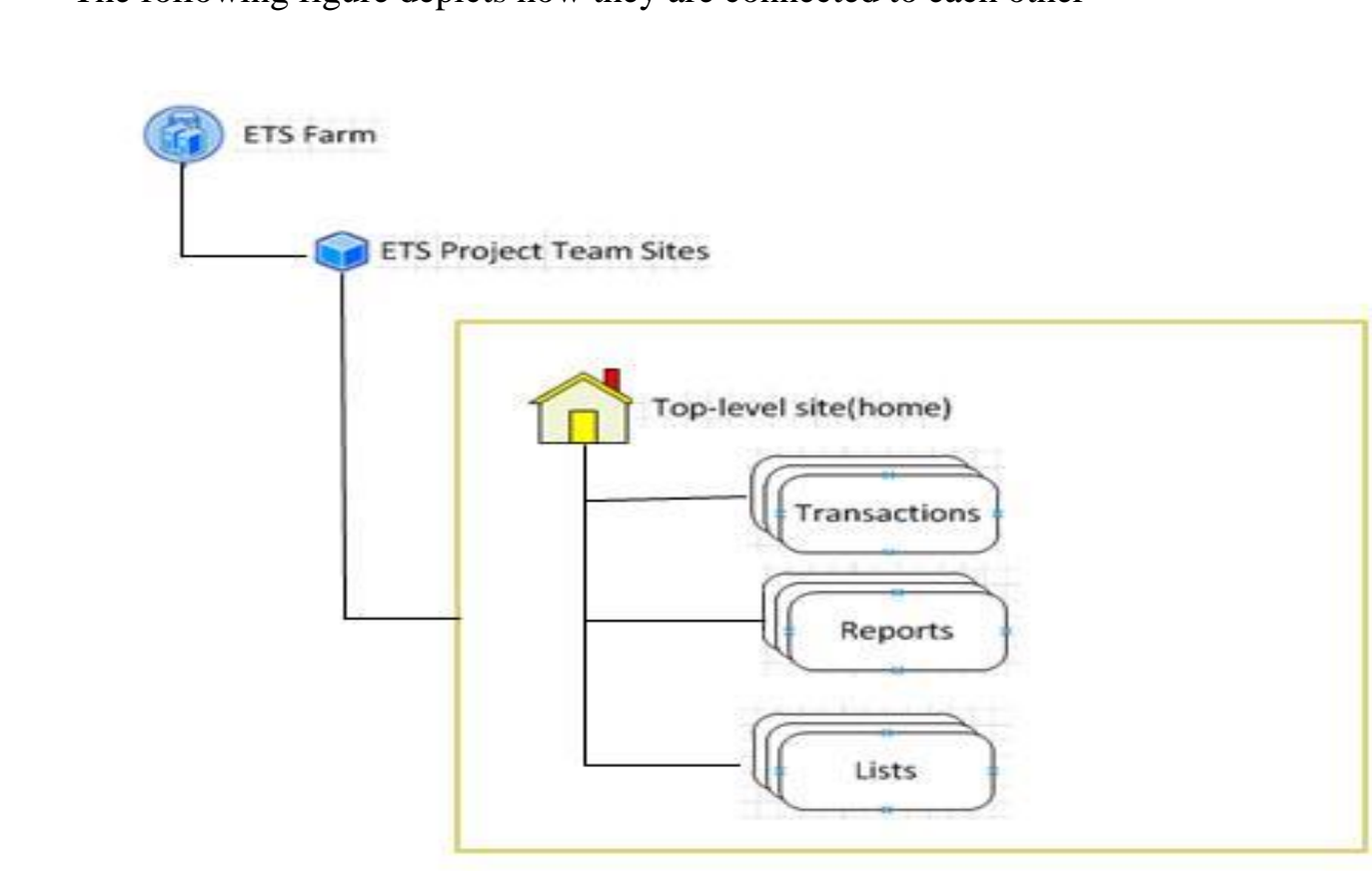

Figure 2. Site Structure in ETS System

Email Reminder - R\&D Employee [Job] (Email Sending Process):

The pending task of an employee can be send as an alert or remainder to the Email. The result of sample table is given below. 
Table 1. Pending Task Remainder

\begin{tabular}{|c|l|}
\hline S.No & \multicolumn{1}{|c|}{ Description } \\
\hline 1 & $\begin{array}{l}\text { Find list of employees from EFFORTTRACKING table whose effort data is less than } \\
100 \% \text { for the current week. }\end{array}$ \\
\hline 2 & Select their email id from employee table \\
\hline 3 & Write a store procedure to send the email reminder by using sp_send_dbmail. \\
\hline
\end{tabular}

The effort tracking system tracks employee working status, task update can be investigated and tracked very easily. This system will help quality assurance team and senior management to get the effort variance detail in each project in just few seconds. The following diagram outlines the proposed functional architecture of the Effort Tracking System.

The ETL solution connects to the Effort Tracking System transaction database tables using SSIS technology extracts the data and loads to Data warehouse and processing the cube on data warehouse. Figure 2 illustrates dimensional model for Data warenouse.

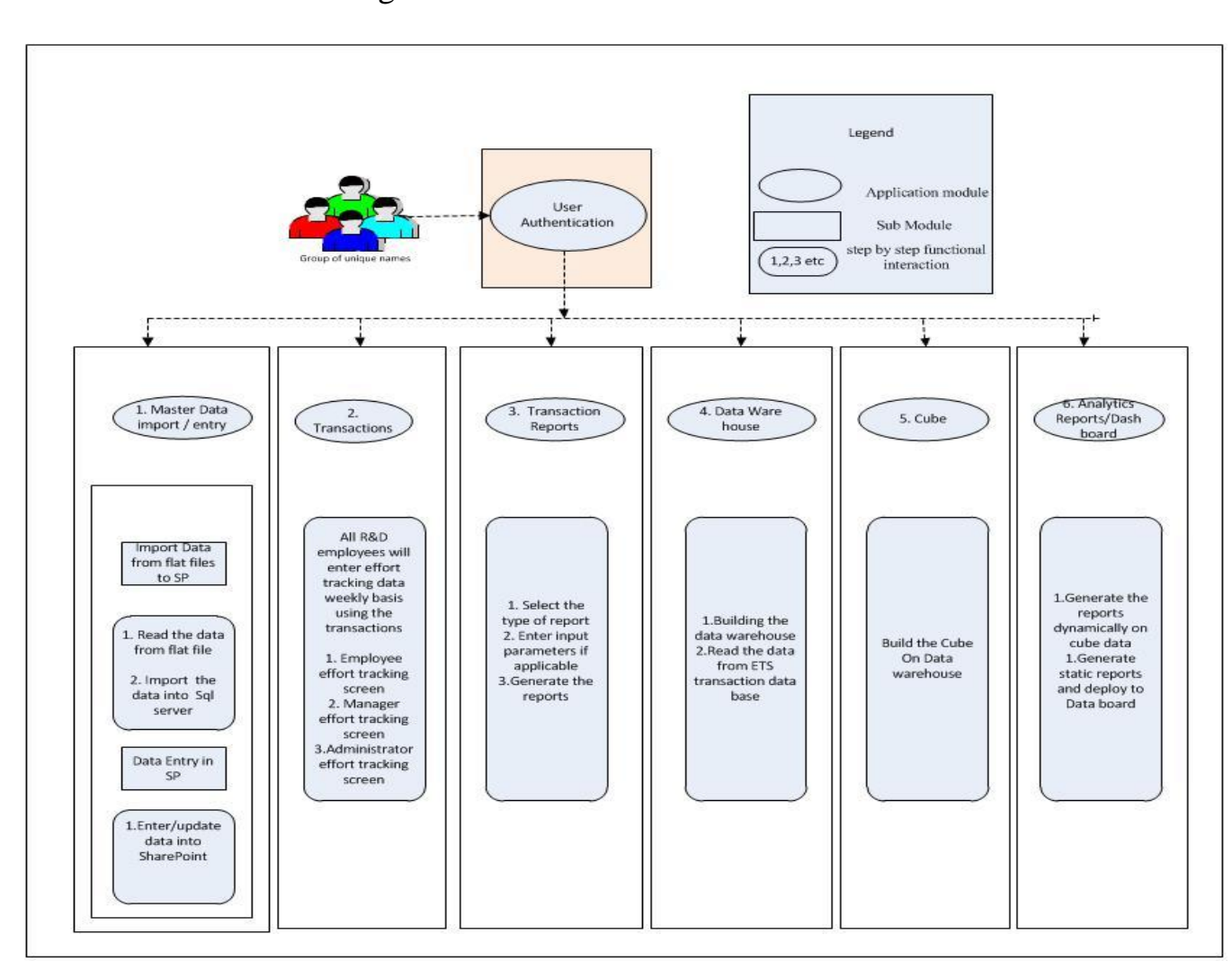

Figure 3. Functional Architecture

\section{External Content Types}

A core concept of Microsoft Business Connectivity Services (BCS) is the external content type. Used throughout the functionality and services offered by Business Connectivity Services, external content types are reusable metadata descriptions of connectivity information and data definitions plus the behaviors you want to apply to a certain category of external data. External content types enable you to manage and reuse the metadata and behaviors of a business entity such as product or project from a central location, and enable users to interact with that external data and processes in a more meaningful way. 
The Test Case:

The test case of a Tracking system can be viewed as a table with sample data.

Table 2. Various Test Cases of Effort Tracking System

\begin{tabular}{|c|c|c|c|c|c|}
\hline Step & Test Steps & Test Data & Expected Result & Actual Result & $\begin{array}{c}\text { Status } \\
\text { (Pass/Fail) }\end{array}$ \\
\hline 1 & $\begin{array}{c}\text { Employee trace } \\
\text { Admin tab }\end{array}$ & HC Tracking & $\begin{array}{l}\text { Not able to see } \\
\text { Admin page }\end{array}$ & $\begin{array}{l}\text { Not able to see } \\
\text { Admin page }\end{array}$ & Pass \\
\hline 2 & $\begin{array}{l}\text { Password } \\
\text { Validation }\end{array}$ & ABC123 & Login Successful & Login Successful & Pass \\
\hline 3 & $\begin{array}{l}\text { Password } \\
\text { Validation }\end{array}$ & BC123 & Login Fail & Login Fail & Fail \\
\hline 4 & Total Effort & $\begin{array}{c}\text { Less Than } \\
100 \%\end{array}$ & Red Signal & Red Signal & Fail \\
\hline 5 & Total Effort & $\begin{array}{c}\text { More than } \\
100 \%\end{array}$ & Red Signal & Red Signal & \\
\hline 6 & Total Effort & Equal to $100 \%$ & Green Signal & Green Signal & \\
\hline 7 & $\begin{array}{l}\text { Manager Weekly } \\
\text { Report accessed by } \\
\text { Admin }\end{array}$ & Report & Not Authorized & & Fail \\
\hline 8 & $\begin{array}{l}\text { Manual spend } \\
\text { Allocation }\end{array}$ & $\begin{array}{l}\text { Finance as } \\
\text { Regular }\end{array}$ & Not & & Fail \\
\hline 9 & $\begin{array}{l}\text { Manual spend } \\
\text { Allocation }\end{array}$ & $\begin{array}{c}\text { Finance as Non } \\
\text { Regular }\end{array}$ & Not & & Fail \\
\hline
\end{tabular}

\section{Benefits of Effort Tracking System}

Some benefits of using effort trackingsystem are:

a) Effort Tracking System aids in measuring the effectiveness of Task health and progress.

b) It measures the efficiency or team and individuals in a particular task involved.

c) It determines the lessons learnt based on the involvement and efforts spent in an activity.

d) The health and progress status helps the senior management to make critical project decisions

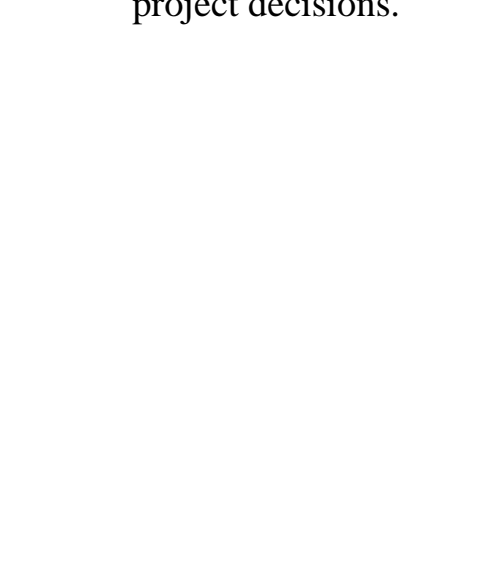




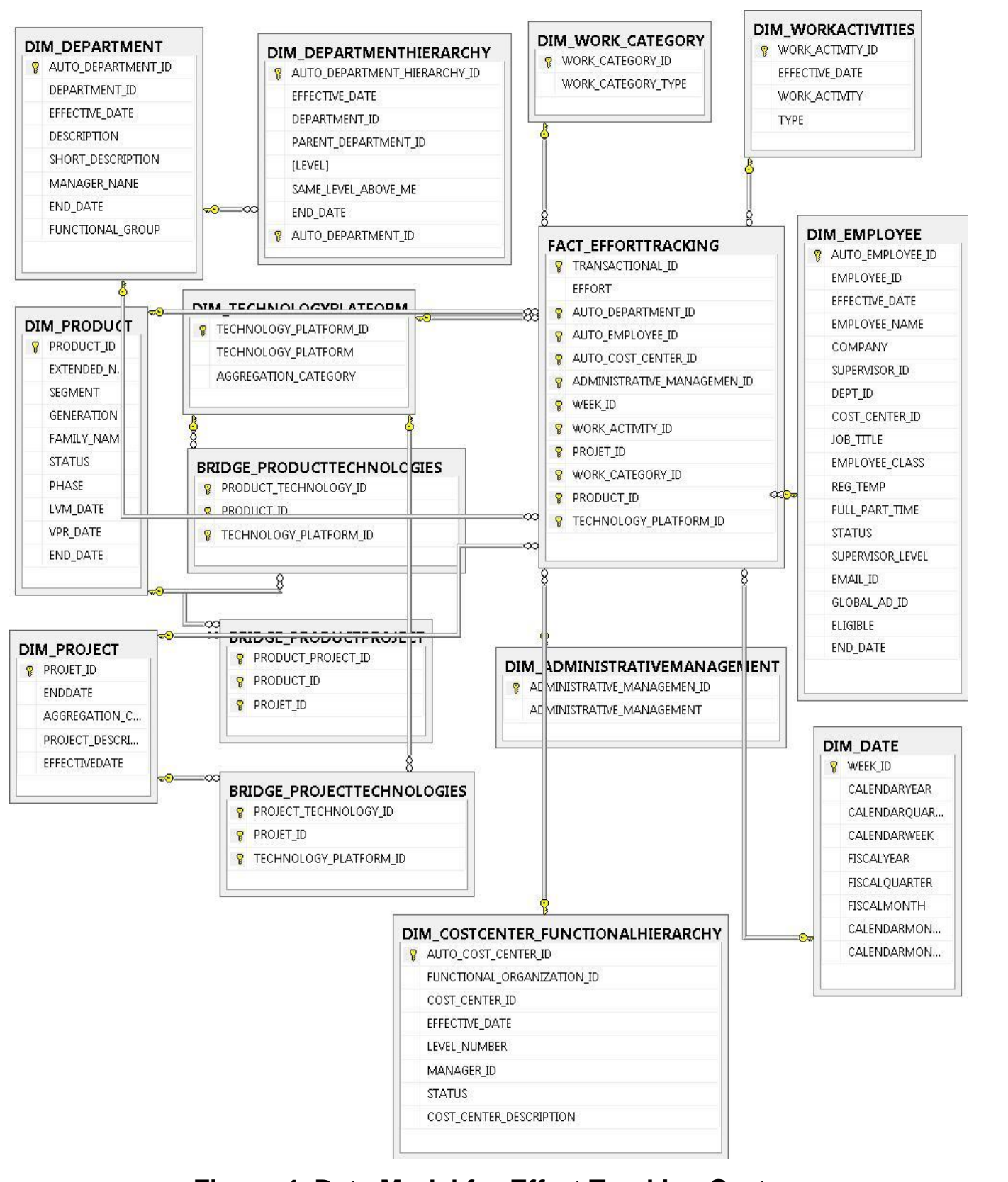

Figure 4. Data Model for Effort Tracking System

\section{Conclusion}

Effort Tracking System results into a clear picture of the involvement of organizational workforce on various projects and the individual efforts absorbed by these projects. Effort tracking in an organization contributes to highlights the lessons learnt during project implementation which can be used to measure the effectiveness of the overall project progress. Implementation of automated tool helps in turning the stable process to mature capable process. 


\section{References}

[1] E. Kazuhiro, Y. Ichinose and S. Yamada, "Statistical Analysis of Process Monitoring Data for Software Process Improvement and Its Application", American Journal of Operations Research, vol. 2, no. 1, (2012), pp. 43.

[2] S. K. Harihara, and U. K. Mishra, "Improving Software Processes using Statistical Process Control and Experimental Design”, Software Engineering and Technology, vol. 3, no. 4, (2011), pp. 167-172.

[3] Y. Shigeru, T. Yamashita, and A. Fukuta, "Product quality prediction based on software process data with development-period estimation", International Journal of Systems Assurance Engineering and Management, Vol. 1, No. 1, (2010), pp. 72-76.

[4] T. Neville, "Measuring Project Health", the Project Perfect White Paper Collection, (2008), pp. 2-3.

[5] Y. Shigeru, and A. Kawahara, "Statistical analysis of process monitoring data for software process improvement", International Journal of Reliability, Quality and Safety Engineering, vol. 16, no. 5, (2009), pp. 435-451.

[6] T. Fukushima and S. Yamada, "Improvement in software projects by process monitoring and quality evaluation activities", Proceedings of the 15th ISSAT International Conference on Reliability and Quality in Design, (2009), pp. 265-269.

[7] S. Yamada and T. Fukushima, "Quality-oriented software management", Morikita-Shuppan, Tokyo, (2007).

[8] B. H. Ahmed, A. D. F. Price and T. M. Hassan, "Performance measurement in construction" Journal of management in engineering, vol. 20, no. 2, (2004), pp. 42-50.

[9] K. K. Gopal, "Performance measurement system", Total Quality Management, vol. 13, no. 5, (2002), pp. 715-728.

[10] S. K. Robert and D. P. Norton, "Transforming the balanced scorecard from performance measurement to strategic management: Part I", Accounting horizons, vol 15, no. 1, (2001), pp. 87104.

[11] Y. Raymond, K. E. Pearlson, and G. Kozmetsky, "Zero Time: Providing Instant Customer Value-Every Time", All the Time. Wiley, (2000).

[12] L. G. Todd and A. Mockus, "Inferring change effort from configuration management databases", Proceedings of IEEE Fifth International Software Metrics Symposium, (1998), pp. 267-273.

[13] M. S. Arthur, "Why balanced scorecards fail", Jounal of strategic performance measurement, vol. 2, no. $11,(1999)$.

[14] N. Andy, "The performance measurement revolution. why now and what next", International journal of operations \& production management vol. 19, no. 2, (1999), pp. 205-228.

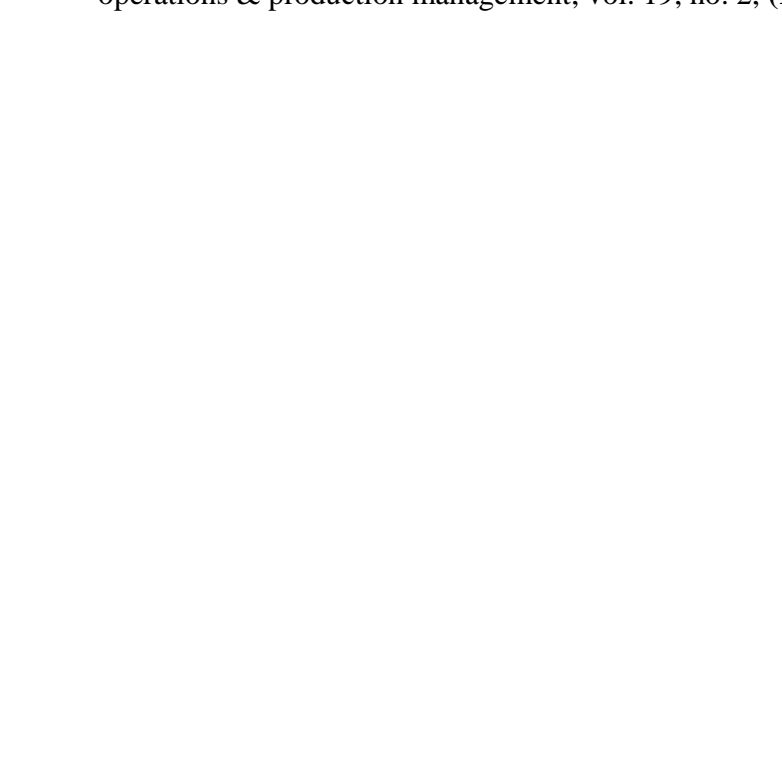


International Journal of Multimedia and Ubiquitous Engineering

Vol.11, No.12 (2016)

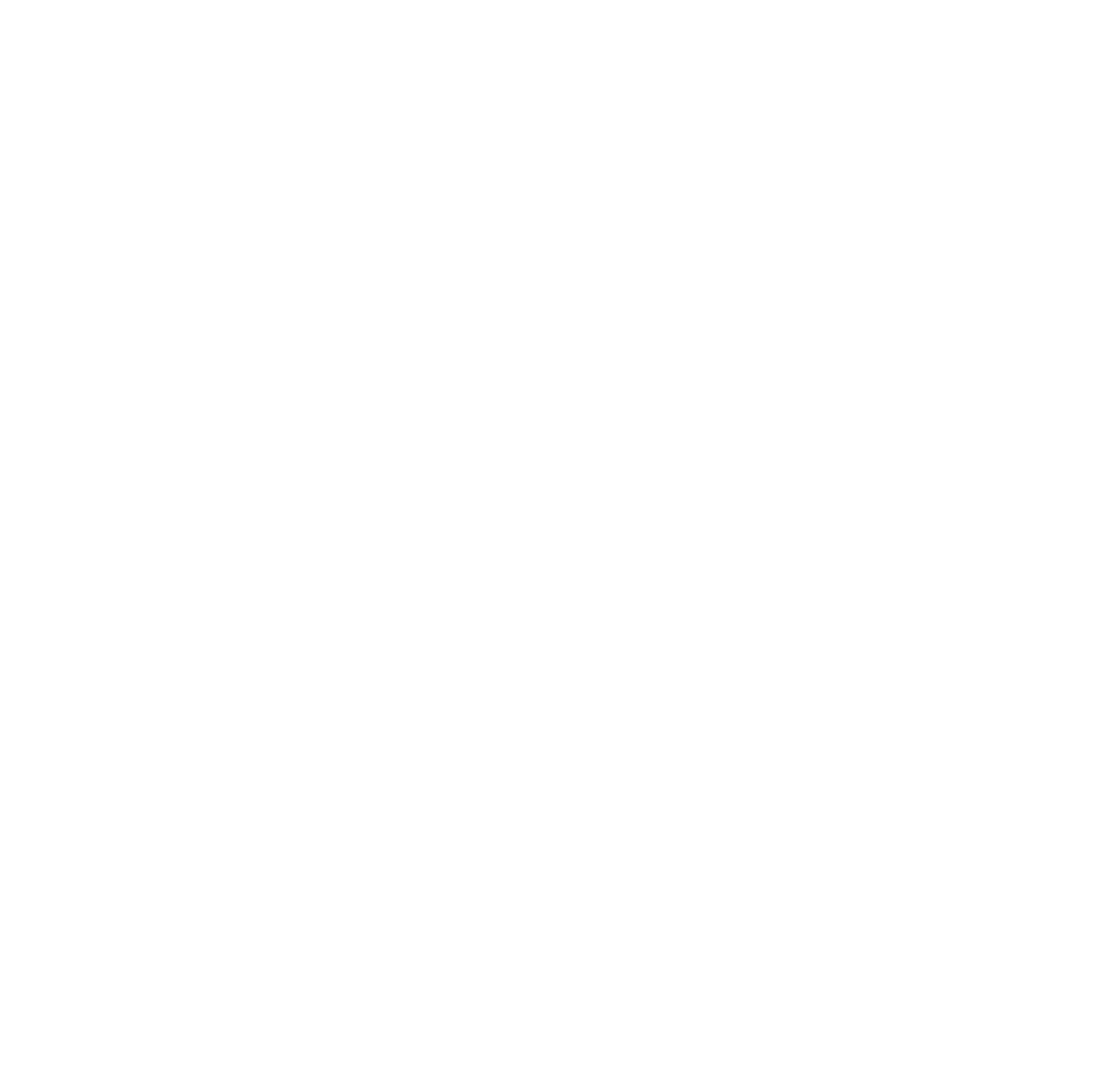

